\title{
Hidrogéis de PoliHEMA para Reparo de Defeitos da Cartilagem Articular. 1 - Síntese e Caracterização Mecânica
}

\author{
Sonia M. Malmonge e Cecília A. C. Zavaglia
}

Resumo: Este trabalho visa a obtenção de hidrogéis de poli(2 hidróxi etil metacrilato) - poliHEMA com propriedades mecânicas adequadas ao uso dos mesmos no reparo de defeitos da cartilagem articular. Para tanto, duas alternativas foram estudadas: a variação da densidade de reticulação e a obtenção de blendas do tipo redes semi interpenetrantes (sIPN) de poliHEMA reticulado e diferentes polímeros como reforço. Amostras de hidrogéis foram obtidas por polimerização térmica e caracterizadas quanto à capacidade de absorção de água e de solução aquosa de $\mathrm{NaCl} 0,15 \mathrm{M}$ e quanto ao comportamento mecânico, através de ensaios de fluência a indentação. Os resultados mostraram que a obtenção de blendas sIPN usando copolímero de MMAAA como reforço é uma alternativa interessante para melhorar as propriedades mecânicas sem diminuir muito a capacidade de absorção de água dos hidrogéis.

Palavras-chave: Hidrogel, poli(2 hidróxi etil metacrilato), indentação, regeneração de cartilagem articular

\section{Introdução}

Polímeros naturais ou sintéticos que incham em água são comumente conhecidos como hidrogéis. Estruturalmente consistem de redes poliméricas tridimensionais, geralmente não cristalinas, capazes de absorver e reter elevadas quantidades de água sem a dissolução da rede polimérica ${ }^{1}$.

Entre os hidrogéis sintéticos, aqueles obtidos a partir da polimerização ou copolimerização do 2 hidroxietil metacrilato, para o qual o termo genérico poliHEMA é largamente empregado, tem recebido muita atenção, principalmente em aplicações biomédicas ${ }^{2}$. O reconhecimento do poliHEMA como um biomaterial em potencial resultou do trabalho de um grupo de pesquisadores da antiga Checkoslováquia, liderados por OTTO WICHTERLE ${ }^{3}$. A partir de seu estudo, teve início a utilização do poliHEMA na confecção de lentes de contato hidrofílicas, apresentando excelentes resultados.

Embora os hidrogéis apresentem vantagens em relação a outros polímeros para a substituição de tecidos moles no organismo, o desenvolvimento de implantes confeccionados a partir deste material tem se deparado com um fator limitante, os baixos valores de resistência mecânica. Porém, acredita-se ser possível melhorar as propriedades mecânicas de hidrogéis de poliHEMA, para serem utilizados como um biomaterial na correção de defeitos da cartilagem articular, surgidos em decorrência de traumas ou doenças degenerativas. 
A cartilagem articular é um material biológico capaz de suportar peso, que recobre as extremidades dos ossos que se articulam nas juntas sinoviais. Tais juntas sustentam elevadas cargas que são aplicadas sob condições cíclicas durante os movimentos do corpo.

Doenças envolvendo as articulações são comuns não só em humanos mas na espécie dos mamíferos em geral. As mais comuns são a osteoartrite ou osteoartrose, condromalacia e osteocondrite dissecante. Além das doenças, cujas causas e mecanismos que as desencadeiam não são bem conhecidos, são comuns as lesões das juntas por traumas mecânicos.

Atualmente, as terapias aplicadas nestes casos vão desde modificações no estilo de vida visando diminuir a atividade da junta, aplicação de diferentes medicamentos, terapia física, as quais podem levar à diminuição dos sintomas sem alterar o curso da doença, e as terapias que envolvem procedimentos cirúrgicos, tais como : artrodese da junta lesada, que alivia a dor em sacrifício da mobilidade da junta; osteotomia do quadril ou joelho, que alivia a dor e, em alguns casos pode levar à formação de nova superfície articular, embora os resultados possam variar consideravelmente entre os diferentes pacientes e, finalmente a substituição da articulação por uma prótese total, o que leva ao alívio da dor e melhoria na atividade da junta. Tais procedimentos entretanto, apresentam limitações, principalmente em casos de pacientes jovens e ativos, uma vez que não permitem a restauração de uma superfície articular com propriedades mecânicas e durabilidade da cartilagem articular.

Nos últimos anos tem se intensificado as pesquisas que buscam o desenvolvimento de procedimentos e terapias alternativas a serem utilizadas nos casos de doenças das juntas, de maneira a restaurar superfícies articulares lesadas. Muitas destas pesquisas envolvem a utilização de diferentes materiais, biológicos ou sintéticos para a restauração da superfície articular nos casos em que a lesão consiste em defeitos com área bem definida.

Implantes de polímero para o reparo de lesões cartilaginosas apresentam um grande potencial, desde que sejam fáceis de produzir, manusear, apresentem comportamento mecânico semelhante ao da cartilagem articular e sejam biocompatíveis. Os polímeros que vêm sendo estudados para tal aplicação dividem-se basicamente em duas categorias :
- materiais biodegradáveis que funcionem como matriz temporária permitindo o crescimento de tecido cartilaginoso para preencher o defeito e restaurar a superfície articular ${ }^{4}$.

- materiais de preenchimento que permitam a restauração de uma superfície articular funcional ${ }^{5-8}$.

Os hidrogéis aqui estudados se enquadram na segunda categoria, visto se tratarem de polímeros não biodegradáveis. Devido a sua similaridade física com a cartilagem, " in vivo", os hidrogéis além de apresentarem complacência semelhante a dos tecidos moles do organismo, não impedem o fluxo de fluidos corpóreos contendo nutrientes e/ou metabólitos para as células, como é o caso do fluido sinovial, uma vez que apresentam elevada capacidade de incorporação de água em sua estrutura e, além disso, apresentam baixo coeficiente de atrito, característica importante para este tipo de aplicação. Assim, hidrogéis com propriedades mecânicas adequadas podem preencher defeitos da cartilagem articular, de forma a restaurar a função da superfície articular. Podem ainda ser revestidos por membranas biológicas com capacidade de formar matriz extracelular cartilaginosa, como é o caso do periósteo, propiciando a sustentação mecânica necessária para que o defeito seja devidamente restaurado através do crescimento de tecido cartilaginoso sobre o hidrogel, sem a formação de incongruências na superfície articular ${ }^{9}$. Outra vantagem dos hidrogéis é a possibilidade de incorporação e liberação controlada de fatores de crescimento, substâncias estas capazes de modular a atividade das células cartilaginosas, os condrócitos.

\section{Hidrogéis de poliHEMA}

Os hidrogéis de poliHEMA são divididos em duas categorias, de acordo com o tamanho de poros em sua estrutura. As diferentes porosidades resultam da utilização de diferentes técnicas de polimerização. A polimerização em massa do HEMA leva a formação de um polímero rígido transparente que quando é imerso em água, incha tornando-se flexível. Esse tipo de material é normalmente considerado não poroso, embora apresente permeabilidade a solutos de baixo peso molecular, o que sugere a existência de poros com dimensões na faixa das dimensões moleculares (nanômetros). Já quando é obtido por polimerização em solução, resulta em material poroso, e o tamanho dos poros aumenta com o aumento da quantidade de 
diluente na solução, sendo possível a obtenção de material microporoso ( 10 a $100 \mathrm{~nm}$ ) e macroporoso ( $100 \mathrm{~nm}-1 \mu \mathrm{m})$. Estes hidrogéis apresentam-se transparentes como os não porosos, e ainda são conhecidos como homogêneos. Quando se emprega um diluente que é um não solvente para o poliHEMA em quantidade que excede a capacidade máxima de inchamento do polímero final, ocorre um processo de separação de fases que vai resultar em hidrogéis opacos, com poros que variam entre 40 e $80 \mu \mathrm{m}$ e, neste caso, são normalmente denominados esponjas ${ }^{10}$.

Os hidrogéis de poliHEMA têm se mostrado bastante versáteis dentro das diferentes áreas da medicina, sendo utilizados na confecção de lentes de contato, nas cirurgias de córnea, como prótese mamária ${ }^{2,10-11}$ e vêm sendo estudados para diferentes aplicações tais como: dispositivos intra uterinos, cirurgias plásticas e buco maxilo facial, cirurgias periodontais, sistemas para liberação controlada de drogas, revestimento de material hemocompatível e outros ${ }^{11-14}$.

Estudos para a utilização de hidrogéis sintéticos no reparo de cartilagem articular vêm sendo realizados desde a década de 70. Em meados de 1973, BRAY \& MERRYL ${ }^{15}$, envolvidos em um programa para desenvolvimento de material sintético a ser utilizado em cirurgias de reconstrução de juntas articulares, sugeriram que hidrogéis poliméricos de poli(álcool vinílico) - (PVA), obtido por reticulação com radiação apresentam algumas propriedades interessantes para a referida aplicação. Mais tarde, dando continuidade a este trabalho, PEPPAS \& MERRYL ${ }^{16}$, utilizaram técnicas de tratamento térmico para melhorar as propriedades mecânicas deste material. Os trabalhos com PVA continuaram com SASADA e seu grupo ${ }^{17-18}$, inclusive com medidas do comportamento frente atrito, porém não são encontradas publicações recentes sobre o assunto.

Quanto ao poliHEMA, KON \& DE VISSER ${ }^{7}$ avaliaram o potencial de esponjas de poliHEMA com diferentes porosidades como material para restauração de defeitos em cartilagens articulares. Esponjas com diferentes tamanhos de poros foram caracterizadas mecanicamente, implantadas em articulações de joelho de coelhos jovens e adultos. Posteriormente foram avaliadas macroscópica e histológicamente 4, 8 e 12 semanas após o implante. Os autores concluíram que esponjas com tamanhos de poros superiores a $50 \mu \mathrm{m}$ apresentam baixa resistência mecânica sendo esmagadas após implante.

PATEL e colaboradores ${ }^{10}$ e DOWNES e colabo- radores ${ }^{20}$ vêm estudando um sistema polimérico baseado no polietil metacrilato e tetrahidro furfuril metacrilato, que apresenta elevada capacidade de absorção de água e, segundo os autores tem mostrado grande potencial como material para reparo de cartilagem. Segundo os autores, a absorção de fluidos vizinhos ao tecido permite que o material incorpore proteínas de matriz tais como fatores de crescimento, o que pode contribuir para o processo de reparo tecidual.

Tais estudos envolvendo hidrogéis poliméricos são indicativos do potencial destes materiais para 0 reparo de lesões da cartilagem articular. Para que se chegue a um procedimento clínico de reparo de defeitos da cartilagem articular usando hidrogel polimérico, os estudos devem prosseguir na busca de um hidrogel com características que permita a obtenção de uma superfície articular biomecanicamente funcional. Para tanto, é importante que o hidrogel apresente comportamento mecânico semelhante ao da cartilagem articular.

\section{A Cartilagem Articular}

A cartilagem articular pode ser considerada como um compósito orgânico poroso inchado em água. É constituída por 2 fases distintas: uma fase fluida, composta de água e eletrólitos, o fluido sinovial e uma fase sólida composta predominantemente por uma complexa rede de colágeno (principalmente do tipo II), onde agregados de proteoglicanos encontram-se entrelaçados. As células cartilaginosas, os condrócitos, alojam-se nos interstícios dessa matriz sólida, a qual comporta-se como um sólido poroso, incompressível e permeável ao fluido sinovial, que proporciona a nutrição das células ${ }^{21}$.

A cartilagem articular apresenta um comportamento viscoelástico derivado de duas fontes distintas: a dissipação viscoelástica da matriz sólida (matriz extracelular) e a resistência ao fluxo do fluido sinovial em relação à matriz sólida permeável.

Quando normal, a cartilagem articular deve ser capaz de executar 2 funções básicas em uma junta sinovial: reduzir as tensões aplicadas ao osso subcondral, pelo aumento da área de contato entre as superfícies e, proporcionar um baixo coeficiente de atrito entre as superfícies, minimizando o desgaste das mesmas. Suas propriedades mecânicas são determinadas pela composição, sendo que a água, seu componente em maior quantidade, exerce grande 
influência em seu comportamento mecânico ${ }^{22}$. Assim sendo, ensaios com cartilagem articular devem ser conduzidos com amostras imersas em uma solução salina que simule o fluido sinovial.

\section{Ensaios de Indentação}

O comportamento reológico da cartilagem articular vem sendo investigado há várias décadas, através de diferentes configurações de deformação tais como a tração uniaxial, compressão confinada ou não, cisalhamento, etc ${ }^{22}$. Porém, o experimento mais comumente utilizado tem sido a indentação, onde uma carga constante é pressionada normalmente à cartilagem com uma ponta plana ou esférica. A Figura 1 ilustra o sistema utilizado para este tipo de teste, o qual apresenta uma grande vantagem sobre os demais por permitir a avaliação do comportamento mecânico da cartilagem articular natural sem a retirada da mesma do osso, evitando assim erros devido a variação da espessura.

Para se obter dados quantitativos é necessário um modelo matemático que relacione a altura de indentação na amostra às propriedades mecânicas do material. Tais modelos têm sido deduzidos a partir das teorias clássicas da elasticidade. Embora a cartilagem articular seja um material viscoelástico, para pequenas deformações, pode ser aproximado a um modelo elástico uma vez que apresenta respostas rápidas a cargas aplicadas.

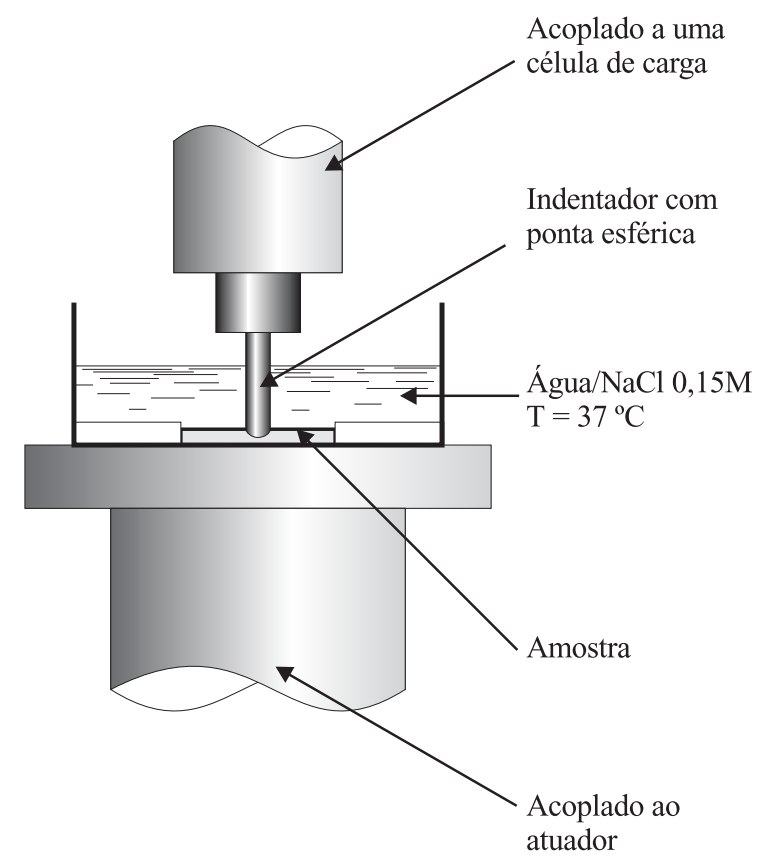

Figura 1. Esquema do ensaio de indentação
KEMPSON e colaboradores ${ }^{23}$ propõem o cálculo do módulo de fluência da cartilagem articular a partir de ensaios de indentação, usando a equação formulada inicialmente por WATERS ${ }^{24}$ para chapas finas de borracha natural vulcanizada.

SWANN $^{25}$ apresenta uma técnica para medida da indentação da cartilagem articular usando um indentador com ponta esférica de raio $1,6 \mathrm{~mm}$ e calcula o módulo de fluência usando a mesma equação utilizada por KEMPSON.

$$
\begin{aligned}
E & =\frac{9 p}{16 \sqrt{r}}\left[\frac{1-\exp (-0.42 e / a)}{h}\right]^{3 / 2} \\
E & =\text { módulo de fluência }\left[\mathrm{Kgf} / \mathrm{cm}^{2}\right] \\
p & =\text { carga }[\mathrm{Kgf}] \\
r & =\text { raio do indentador }[\mathrm{cm}] \\
e & =\text { espessura da amostra }[\mathrm{cm}] \\
h & =\text { altura de indentação }[\mathrm{cm}]
\end{aligned}
$$

Assim sendo, este trabalho apresenta um estudo realizado para a obtenção de hidrogéis de poliHEMA com propriedades mecânicas que permitam sua utilização na correção de defeitos da cartilagem articular, de forma a restaurar uma superfície funcional. Para tanto, duas alternativas foram foram estudadas: a obtenção de hidrogéis de poliHEMA com diferentes quantidades de agente de reticulação e a obtenção de blendas do tipo redes semi interpenetrantes (SIPN) de poliHEMA reticulado com acetato de celulose (AC) ou poli(metacrilato de metila-co-ácido acrílico) poli(MMA-co-AA) como recheio. Os hidrogéis obtidos foram caracterizados quanto ao comportamento mecânico através de ensaios de fluência a indentação, utilizando metodologia semelhante a empregada para avaliação do comportamento mecânico de cartilagem articular, descrita acima.

\section{Experimental}

\section{Síntese de Hidrogéis}

Amostras de hidrogéis foram obtidas através da polimerização térmica utilizando-se peróxido de benzoíla como iniciador. O monômero base utilizado foi o 2 hidróxi etil metacrilato - HEMA (Aldrich) e o agente de reticulação foi o trimetilolpropano trimetacrilato - TMPTMMA (Rohm \& Haas). 
Para a obtenção de amostras na forma de filmes, a solução a ser polimerizada era vertida num molde constituído de duas placas de vidro separadas por uma gaxeta de teflon com $2 \mathrm{~mm}$ de espessura e presas externamente por garras e parafusos e a seguir levada a temperatura de $80{ }^{\circ} \mathrm{C}$ durante 4,0 horas. Após o resfriamento as amostras eram deixadas em água destilada e deionizada para a remoção de monômero e iniciador residuais.

\section{Síntese de Blendas SIPN}

Foram sintetizadas também blendas sIPNs, utilizando diferentes polímeros como reforço: acetato de celulose - AC (Rhodia) com grau de substituição 2,5 e copolímeros de metacrilato de metila (MMA) e ácido acrílico (AA), sintetizados por polimerização térmica a partir da mistura de monômeros de MMA (Metacril) e AA (Rohm \& Haas), na proporção MMA:AA de 75:25. Para a obtenção das amostras de blenda, o polímero reforço era inicialmente dissolvido em solvente adequado (acetona ou álcool etílico) e adicionado à solução de monômero, iniciador e agente de reticulação nas concentrações desejadas, formando a solução a ser polimerizada conforme já descrito.

\section{Caracterização}

Amostras obtidas a partir de diferentes concentrações dos constituintes foram caracterizadas quanto à capacidade de absorção de água ( $\left.\chi_{\text {água }}\right)$ e de uma solução de água/ $\mathrm{NaCl} 0,15 \mathrm{M}\left(\chi_{\text {água/ } \mathrm{NaCl}}\right)$. Escolheu-se $0,15 \mathrm{M}$ para simular o fluido sinovial. O comportamento mecânico das amostras foi determinado através de ensaios de fluência à indentação.

\section{- Absorção de água e água/NaCl}

Para a determinação de $\chi_{\text {água }}$ e $\chi_{\text {água/NaCl }}$ pequenas amostras do hidrogel eram devidamente secas sob vácuo, pesadas e a seguir imersas em água destilada e deionizada ou solução de água/ $/ \mathrm{NaCl}$ $0.15 \mathrm{M}$ até atingirem o equilíbrio (peso constante). $\chi_{\text {água }}$ e $\chi_{\text {água/ } \mathrm{NaCl}}$ eram então determinados como valores médios para 5 determinações para cada amostra.

$$
\chi_{\text {água }}=\mathrm{m}_{\text {água no gel }} / \mathrm{m}_{\text {gel }}
$$

$$
\chi_{\text {agua/NaCl }}=\mathrm{m}_{\text {água/ } / \mathrm{NaCl} \mathrm{no} \mathrm{gel}} / \mathrm{m}_{\text {gel }}
$$

onde :

$$
\begin{aligned}
\mathrm{m}_{\text {água no gel }}= & (\text { massa amostra inchada em água } \\
& - \text { massa amostra seca }) \\
\mathrm{m}_{\text {água } / \mathrm{NaCl} \mathrm{no} \mathrm{ge} \mathrm{I}}= & (\text { massa amostra inchada em água/ } \\
& \mathrm{NaCl}-\text { massa amostra seca }) \\
\mathrm{m}_{\text {ge l } \mathrm{I}}= & \begin{array}{l}
\text { massa amostra inchada em água } \\
\text { ou água } / \mathrm{NaCl}
\end{array}
\end{aligned}
$$

\section{- Ensaios de Indentação}

O estudo do comportamento mecânico foi feito através de ensaios de fluência à indentação, com ponta esférica de raio $1,6 \mathrm{~mm}$ utilizando um sistema conforme o ilustrado na Figura 1, o qual foi acoplado a uma máquina universal de ensaios mecânicos (MTS - modelo 810). Durante o ensaio a amostra era mantida imersa em solução de água/ $\mathrm{NaCl} 0,15$ $\mathrm{M}$, sob temperatura controlada de $37^{\circ} \mathrm{C}$. Para todas as amostras a carga aplicada foi de $0,5 \mathrm{Kgf}$, durante 120 segundos, após o que era imediatamente retirada. Era registrada a altura de indentação (h) ao longo do tempo. A partir de tais dados e da equação 1 foi possível o cálculo do módulo de fluência à indentação (E) para as diferentes amostras. Para o cálculo de E, escolheu-se tomar h medido após 2,0 segundos de aplicação da carga, pois acreditamos que para pequenas deformações as amostras apresentaram comportamento mais próximo do elástico.

\section{Resultados e Discussão}

As amostras obtidas apresentaram-se como filmes rígidos quando totalmente secas, tornando-se complacentes quando inchadas em água ou em solução aquosa de $\mathrm{NaCl}$ 0,15 M. Todas as amostras apresentaram $\chi_{\text {água }}$ maior que $\chi_{\text {água/ } \mathrm{NaCl}}$ conforme esperado, devido a pressão osmótica da solução, o que diminui a força motriz para a entrada de água para o hidrogel.

A capacidade de absorção de água e de solução de $\mathrm{NaCl}$ e consequentemente a complacência das amostras variaram em função da quantidade de agente reticulante (AR) utilizado para a síntese do poliHEMA reticulado e em função da quantidade e tipo de polímero utilizado como reforço nas blendas sIPN, conforme mostram os resultados a seguir: 
PoliHEM A Reticulado

A Figura 2 mostra a altura da indentação ao longo do tempo para a aplicação de uma carga de 0,5 Kgf durante 120 segundos, após o que a carga era retirada rapidamente. Observa-se que o aumento da concentração de AR de 0 a $10 \%$ reduz drasticamente a altura de indentação.

Na Figura 3 é possível observar que o módulo de fluência $\left(E_{2 s}\right)$, obtido a partir do ensaio de creep para 2,0 seg de aplicação de carga aumenta enquanto $\chi_{\text {água/ } / \mathrm{NaCl}}$ diminui em função do aumento da concentração de AR. O aumento da densidade de reticulação aumenta a coesão da rede e em consequência diminui a capacidade de absorção de água e água $/ \mathrm{NaCl}$. A água no interior do hidrogel funciona como plastificante afastando as cadeias poliméricas, o que causa um aumento na complacência das amostras e por isso, quanto maior a quantidade de água no interior da amostra, menor é o seu módulo de fluência $\left(E_{2 s}\right)$.

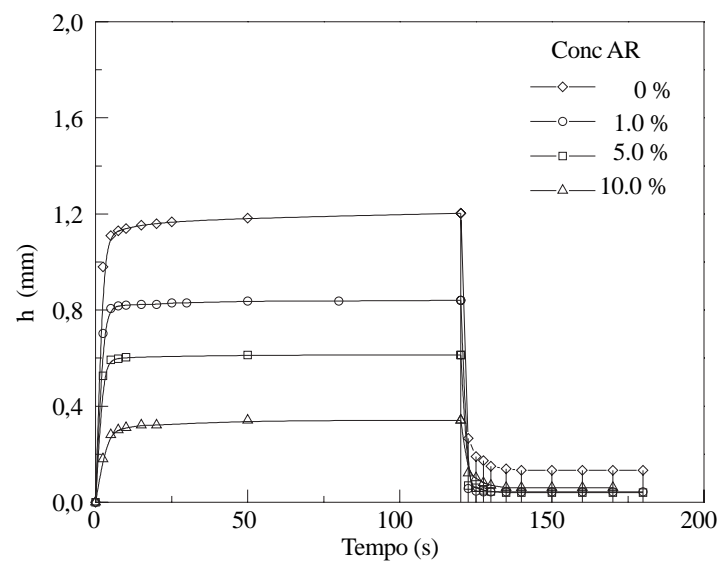

Figura 2. Altura de indentação $\mathrm{x}$ tempo para poliHEMA reticulado.

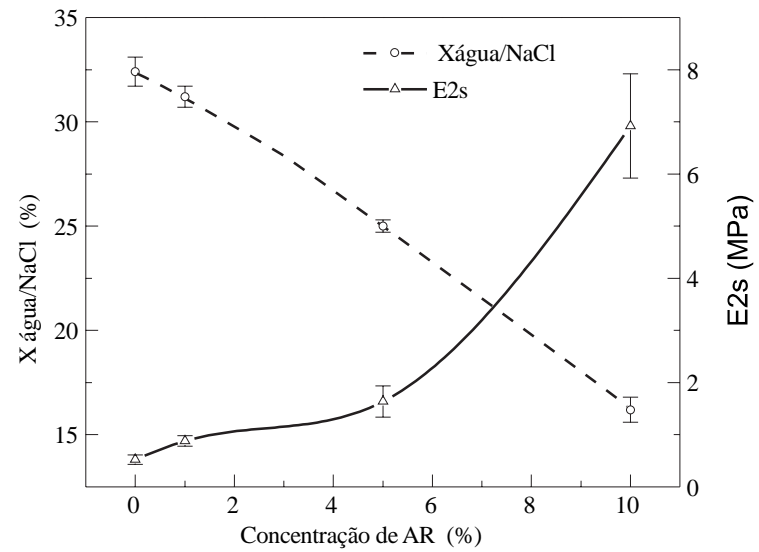

Figura3. $\chi_{\text {agua/NaCl }}$ e $E_{2 \mathrm{~s}} \mathrm{x}$ concentração de AR para poliHEMA reticulado.
Blendas sIPN com AC.

As Figuras 4 e 5 mostram o comportamento das amostras de blendas sIPN formadas de poliHEMA reticulado $(1,0 \% \mathrm{AR})$ reforçado com diferentes quantidades de AC. Tais resultados comprovam a formação de estrutura a nível molecular, semelhante a estrutura de um material compósito, onde o polímero não reticulado usado como recheio funciona como reforço para o polímero reticulado.

Neste caso, as cadeias do poliHEMA encontramse entrelaçadas pelas cadeias de AC e assim, o aumento da concentração de $\mathrm{AC}$ aumenta a coesão da rede diminuindo a capacidade de absorção de água e água/ $\mathrm{NaCl}$. O módulo de fluência $\left(\mathrm{E}_{2 \mathrm{~s}}\right)$ aumenta com a quantidade de $\mathrm{AC}$, porém não ultrapassa 1,2 $\mathrm{MPa}$, mesmo para concentrações de até $10,0 \%$ de AC. Não foi possível obter amostras com concentração de AC superiores a $10,0 \%$, devido a baixa solubilidade deste no HEMA. Assim sendo, partiu-se para o estudo da blenda sIPN usando outro polímero como reforço.

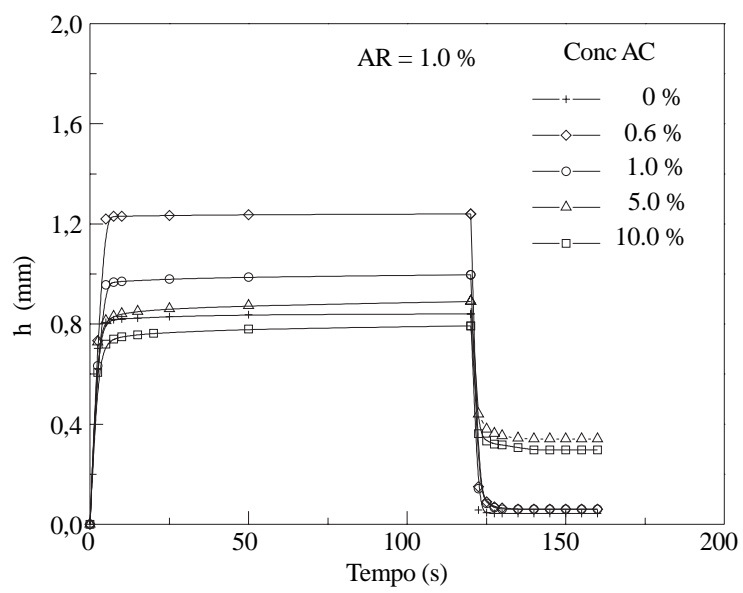

Figura 4. Altura de indentação x tempo para blendas sIPN de poliHEMA com AC.

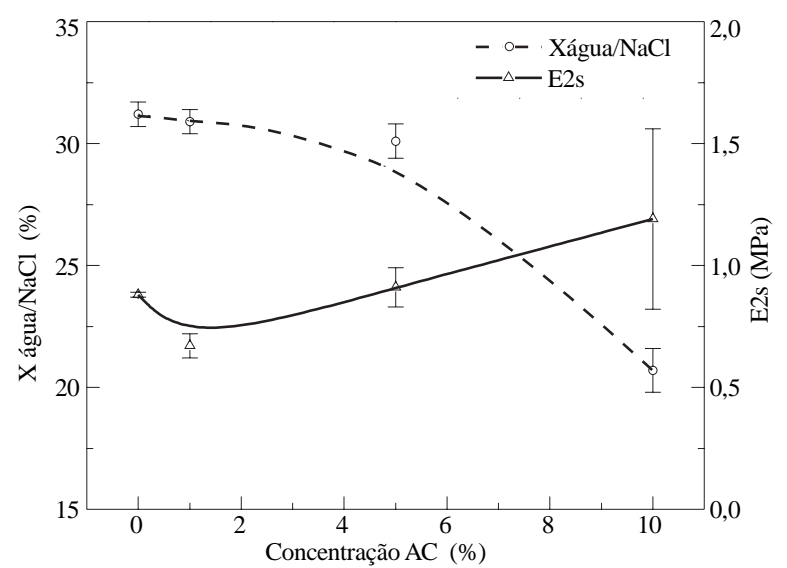

Figura 5. $\chi_{\text {agual } \mathrm{NaCl}}$ e $\mathrm{E}_{2 \mathrm{~s}} \mathrm{x}$ concentração de $\mathrm{AC}$ para blendas sIPN de poliHEMA com AC. 


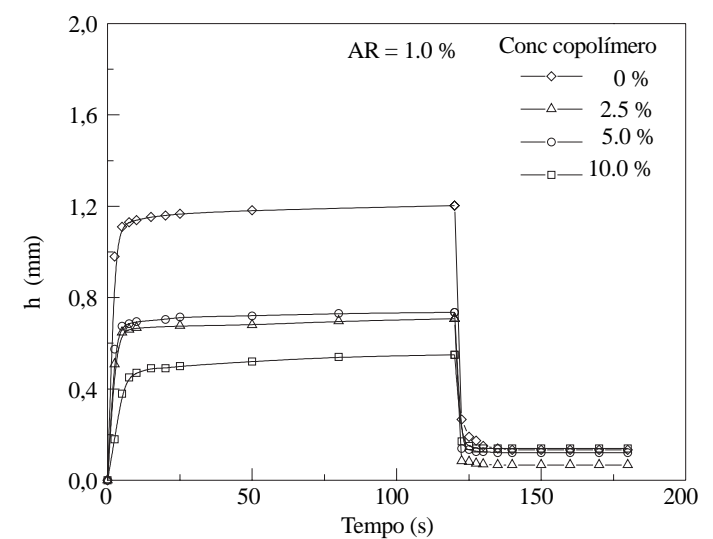

Figura 6. Altura de indentação $x$ tempo para blendas sIPN de poliHEMA com poli(MMA-co-AA).

Blendas sIPN com Poli(metacrilato de metila-coácido acrílico).

Tendo em vista que o aumento de $\mathrm{E}_{2 \mathrm{~s}}$ foi pequeno para as blendas sIPN de poliHEMA com AC e que o aumento da quantidade de AR apresentou como inconveniente uma grande queda na capacidade de absorção de água pelo poliHEMA reticulado, estudou-se então o comportamento de blendas sIPN de poliHEMA com poli(MMA-co-AA). Foi escolhido o copolímero de MMA e AA obtido a partir de uma proporção 75:25, para garantir a insolubilidade do mesmo em água. Caso isso acontecesse, o polímero reforço seria dissolvido e arrastado para fora da rede quando imerso em água.

As Figuras 6 e 7 mostram que neste caso foi possível aumentar o módulo de fluência sem grande prejuízo da capacidade de absorção de água.

Para que possa ser utilizado no reparo de defeitos da cartilagem articular, além de um valor elevado de E, é desejável que o material apresente elevada capacidade de absorção de água, como é o caso da cartilagem natural. A Figura abaixo apresenta o comportamento de $\mathrm{E}_{2 \mathrm{~s}}$ em função de $\chi_{\text {águal }}$ $\mathrm{NaCl}$ para os diferentes hidrogéis estudados.

Para o poliHEMA reticulado, bem como para a blenda sIPN com MMA-AA, foi possível aumentar o valor do módulo de fluência $\left(\mathrm{E}_{2 \mathrm{~s}}\right)$ para valores de até 7,0 e 4,0 MPa respectivamente, enquanto que no caso da blenda sIPN com AC o valor do módulo permaneceu aproximadamente constante, abaixo de 1,2 MPa. Verifica-se ainda que para um mesmo valor de módulo de fluência, a blenda SIPN com MMA-AA apresenta $\chi_{\text {água/ } \mathrm{NaCl}}$ maior do que os demais hidrogeis.

Durante o ensaio de indentação do hidrogel, a penetração da ponta é devido à deformação da rede polimérica e à deformação consequente do escoamento

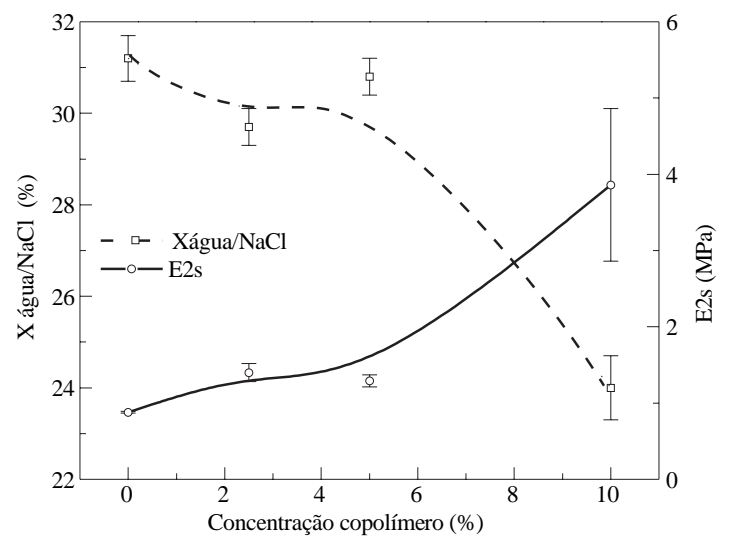

Figura 7. $\chi_{\text {aqua } \mathrm{NaCl}}$ e $\mathrm{E}_{2 \mathrm{~s}} \mathrm{x}$ concentração de $\mathrm{AC}$ para blendas sIPN de poliHEMA com poli(MMA-co-AA).

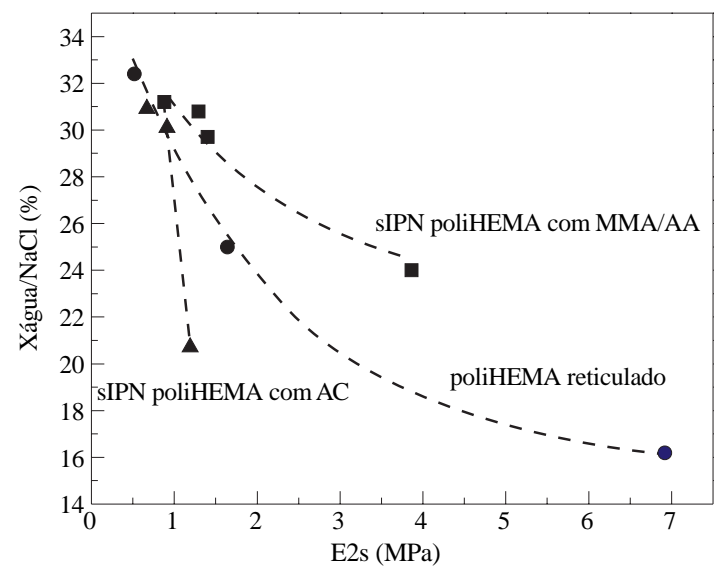

Figura 8. $\mathrm{E}_{2 \mathrm{~s}} \mathrm{x} \chi_{\text {ioua } \mathrm{NaCl}}$ para sIPN com AC como reforço, poliHEMA reticulado e sIPN com MMA-AA como reforço.

de água para fora do hidrogel. Assim sendo, no caso da blenda reforçada com copolímero de MMA-AA, o hidrogel é menos flexível do que nos demais casos. O reforço de copolímero confere maior rigidez a rede e ainda, devido a presença dos grupamentos $\mathrm{COO}^{-}$, íons $\mathrm{Na}^{+}$permanecem no interior do hidrogel para o balanceamento eletrônico, o que provavelmente dificulta a saída da água que tende a permanacer no hidrogel solvatando os íons. Esse comportamento é semelhante ao descrito para a cartilagem articular por MOW e colaboradores ${ }^{21}$. Por isso, dentre os três hidrogéis aqui estudados, as blendas sIPN usando copolímero de MMA-AA como reforço parece ser o mais indicado para a utilização na correção de defeitos da cartilagem articular.

\section{Conclusões}

É possível melhorar as propriedades mecânicas de hidrogéis de poliHEMA através do aumento da concentração do agente de reticulação ou da obtenção de blendas sIPN. 
As amostras aqui estudadas apresentaram propriedades mecânicas inferiores as da cartilagem articular natural. KEMPSON ${ }^{23}$, em seu estudo para determinação do módulo de fluência para a cartilagem articular de fêmur humano, utilizando testes de indentação semelhantes ao utilizado neste estudo, obteve valores de módulo de fluência de até 10,0 MPa. Porém com a aplicação de 0,92 Kgf, com indentador esférico de mesma dimensão do aqui utilizado.

Dentre os hidrogéis aqui estudados, aqueles obtidos a partir das blendas sIPN de poliHEMA com poli(MMA-co-AA) são os mais adequados para o preenchimento de defeitos da cartilagem articular. Para tanto, pode se escolher uma concentração de AR e polímero reforço que otimizem o comportamento mecânico e a capacidade de absorção de água do hidrogel.

É desejável que o material de preenchimento do defeito articular seja poroso, ao menos na superfície inferior, para facilitar sua fixação ao local do implante devido ao crescimento de tecido para dentro dos poros e consequente embricamento mecânico. O material poroso apresentará uma diminuição nas propriedades mecânicas e permitirá incorporação de maior quantidade de água em relação ao material não poroso.

Assim sendo, as próximas etapas deste trabalho consistirão do estudo do comportamento mecânico de hidrogéis porosos bem como a determinação da biocompatibilidade e bioperformance dos hidrogéis aqui estudados frente a regeneração de defeitos da cartilagem articular em animais.

\section{Agradecimentos}

Ao CNPq pelo apoio financeiro. Ao DEMA-FEMUNICAMP pelo apoio e infra-estrutura.

\section{Referências Bibliograficas}

1. Kudela, V., Enc. of Polymer Science and Engineering, John Wiley \& Sons, V7, 783-807, (1990).

2. Ratner, B. D. and Hoffman, A., Acs Symposium Series, 31, 1-36, (1976).

3. Wichterle, O., Nature, 185, 117-118 (1960).

4. Freed, L.E.; Grande, D.A.; Lingbin, Z. ; Emmanual, J.; Marquis, J.c. and Langer, P., Journal of Biomedical Material Research, 28, 891-899 (1994).

5. Minns, R.J.; Muckle, D.S.; Donkin, J.E., Biomaterials, 3, 81-86, (1982)
6. Hanff, G.; Sollerman, C.; Abrahamsson, S.O. and Lundborg, G., Scandinavian Journal of Plastic Reconstructive Hand Surgery, 24, 217-223, (1990).

7. Kon, M. and De Visser, A.C., Plastic and Reconstructive Surgery, 67.3, 289-293, (1981).

8. Downes, S.; Archer, R.S.; Kayser, M.V.; Patel, M.P. and Bradem, M., Journal of Materials Science - Materials In Medicine, 5, 88-95, (1994).

9. Mow, V. C. ; Ractliffe, A. ; Rosenwasser, M. P. and Buckwalter, J.A., Transactions of Asme, J. of Biomechanical Engineering, 113, 193-207 (1991).

10. Chirila, T.V.; Constable, I.J.; Crawford, G.J.; Vijayasekaram, S.; Thompson, D.E.; Chen, Y.C.; Fletcher, W.A. and Griffin, B., Biomaterials, 14.1, 26-38, (1993).

11. Pedley, D.G.;Skelley, P.J. and Tighe, B.J., The British Polymer Journal, Vol. 12, 99-110 (1980).

12. Stastny, K.; Hora,K. and Stol, M., Biomaterials, V14-14, 1105-1108, (1993).

13 Zavrel, V. and Stol, M., Biomaterials, V14-14, 11091112, (1993).

14 Ambrósio, L.; Netti, P.A.; Jannall, S. Huang, S.J. and Nicolais, L., Journal of Materials Science : Materials In Medicine, V7, 251-254, (1996).

15 Bray, J. C. and Merryl, E. W., Journal of Biomedical Materials Research, V 7, 431-443, (1973).

16 Peppas, N. A. and Merril, E. W., Journal of Biomededical Materials Research, V.11, 123-434, (1977).

17 Sasada, T., Journal of Japanese Society For Biomaterials, 3, 151-157, (1985).

18 Sasada,T., Abstracts of Third World Biomaterials Congress, P.21-25 April, 6, (1988).

19 Patel,M.P., Braden, M. and Downes, S., Journal of Materials Science:Materials In Medicine, V.5, 338-229, (1994).

20 Downes, S; Archer,R.S.; Kayser, M.V.; Patel, M.P. and Braden, M., Journal of Materials Science - Materials In Medicine, V. 5, 88-95, (1994).

21. Mow, V. C. ; Ractliffe, A. and Poole, A.R., Biomaterials, 13/2 67-97 (1992).

22. Woo, S.L.Y., Mow, V.C. and Lai, W.M., Handbook of Bioengineering, Cap 4

23. Kempson, G. E. ; Freeman, M.A.R. and Swanson, S.A, J. Biomechanics, Vol. 4,, 239-250 (1971).

24. Waters, N. E., Brit. J. Appl. Phys., Vol. 16, 556-563 (1965).

25. Swann, A. C. and Seedhom, B. B., Proc. Instn. Mech. Engrs. Part H: J. of Eng. In Medicine, Vol. 203, 143-150 (1989). 